\title{
A User's Guide to the Human Genome
}

T G Wolfsberg, K A Wetterstrand, M S Guyer, F S Collins \& A D Baxevanis

Nature Genet. 32, 1-79 (2002).

doi:10.1038/ng977

Owing to a production error, Figure 11.2 was inadvertently inserted in place of Figure 12.2 in both the print and online PDF versions of the User's Guide. The screen in the full text version online is the correct Figure 12.2, and is pictured here.

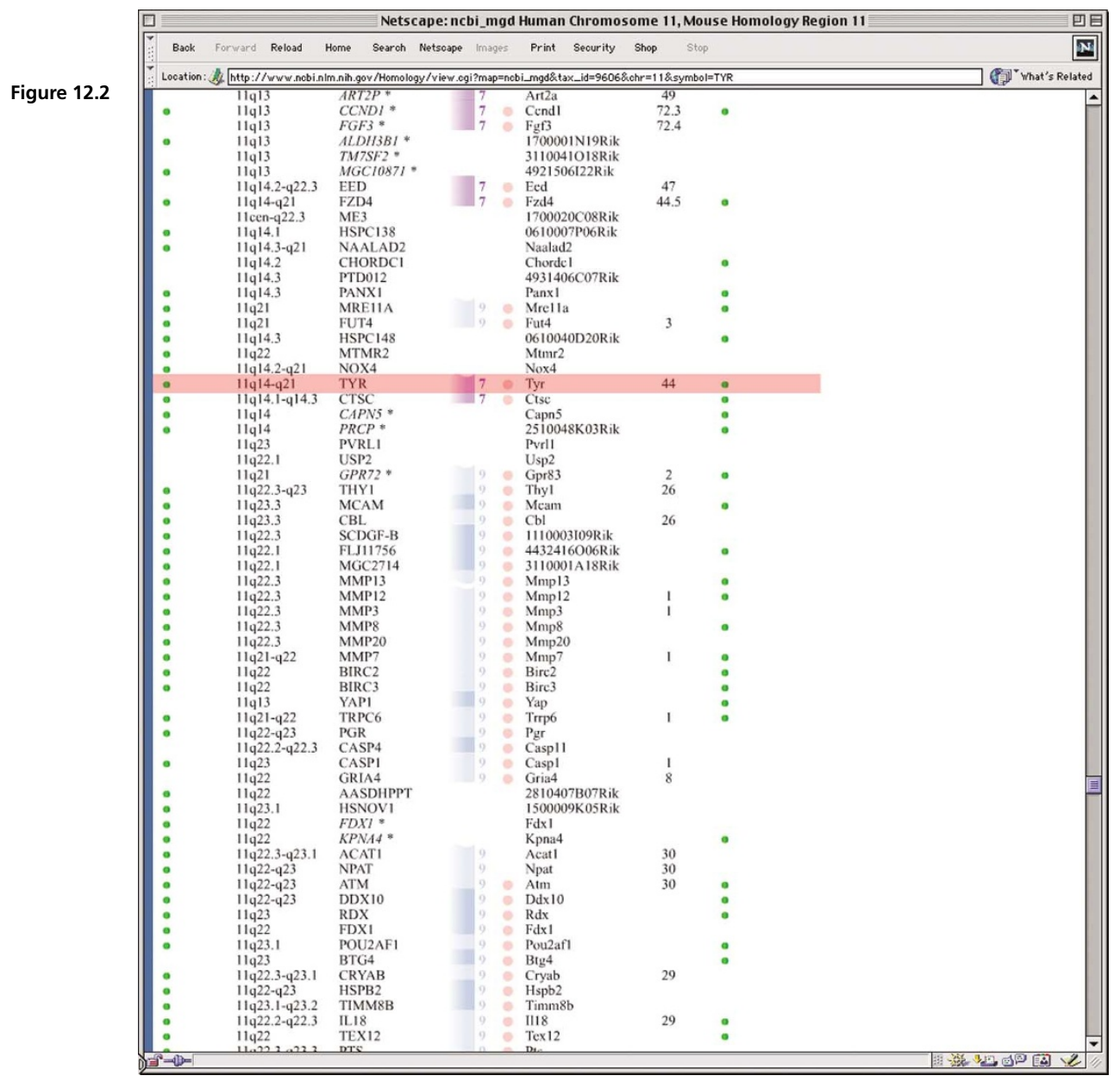

